\title{
Kocatepe Veterinary Journal
}

Kocatepe Vet J (2016) 9(4): 327-331

DOI: $10.5578 / \mathrm{kvj} .35303$

Submittion: 14.10 .2016

RESEARCH ARTICLE

Accepted: 23.11 .2016

\author{
Afyon İlinde Saanen Keçilerinde Eimeria Türlerinin Yaygınlığı \\ Hatice ÇİÇEK ${ }^{1 *}$, Feride SEVİMLI் $^{1}$, Mustafa ESER $^{2}$, Abuzer ACAR $^{3}$ \\ 1 Afyon Kocatepe Üniversitesi Veteriner Fakültesi Parazitoloji Anabilim Dal, Afyonkarabisar/TÜRKIYYE \\ ${ }^{2}$ Anadolu Üniversitesi Açıö̈gretim Fakültesi Laborant ve Veteriner Sağhk Bölümüu,Eskişshir/TÜRKIYYE \\ ${ }^{3}$ Afyon Kocatepe Üniversitesi İ̧ Hastalıklar Anabilim Dal, Afyonkarabisar/TÜRKİYE \\ Corresponding author e-mail: hcicek@aku.edu.tr \\ \# Bu çalışma, Afyon Kocatepe Üniversitesi Bilimsel Araştırma Proje Komisyonu tarafindan 16.Kariyer.57 kodu ile desteklenmiştir.
}

ÖZ

Afyonkarahisar ilinde 187 Saanen keçisine ait dışkı numunesi, Eimeria türlerini ve perevalansını belirlemek amacıyla muayene edilmiştir. Gram dışkıdaki ookist sayısı (OPG) Modifiye McMaster tekniği ile belirlenmiştir. Gram dışkıdaki ookist sayısı 2-1276 arasında tespit edilmiştir. Dişkı numunelerinde ookistler flotasyon tekniği kullanılarak belirlenmiş, sporlandırılmış ve morfolojik özelliklerine göre teşhis edilmişlerdir. Eimeria ookistleri dışkı numunelerinin \% 39.6'da bulunmuş, sekiz Eimeria türü teşhis edilmiştir. En yaygın türlerin Eimeria caprina (\% 43.2) ve E.ninakoblyakimovae (\% 33.8) olduğu saptanmiştır. Diğer türler E. aspheronica (25.7 \%), E. caprovina (21.6 \%), E. alijevi (18.9 \%), E.jolchijevi (5.4 \%), E. christenseni (2.7\%), E. arloingi $(2.7 \%)$ ve teşhis edilemeyen Eimeria türleri olarak (12.2\%) belirlenmiştir.

Anahtar Kelimeler: Koksidiosis, Eimeria, Saanen Keçisi

\section{Prevalence of Coccidial Infection of Saanen Goats in Afyonkarahisar Province}

\begin{abstract}
Fecal samples from 187 Saanen goats in Afyonkarahisar province examined to determine the prevalence and intensity of the multiple species of Eimeria that infect the goats in this region. The number of oocysts per gram of feces (OPG) was determined by the modified McMaster technique. The number of oocysts per gram of feces (OPG) were found range 2 1276. Oocysts in faecal samples were detected using a flotation technique, sporulated and identified to species based on morphological features of the sporulated oocysts. Eimeria oocysts were found in $39.6 \%$ of the fecal samples. Eight species of Eimeria were identified. Eimeria caprina (43.2 \%) and E.ninakohlyakimovae (33.8\%) were the most prevalent species. Other species present were E. aspheronica (25.7\%), E. caprovina (21.6\%), E. alijevi (18.9\%), E.jolchijevi (5.4\%), E. christenseni (2.7 $\%)$, E. arloingi $(2.7 \%)$, and unidentified Eimeria species $(12.2 \%)$.
\end{abstract}

Key Words: Coccidiosis, Eimeria, Saanen Goats

To cite this article: Çİçek H, Sevimli F, Eser M, Acar A. Afyon İlinde Saanen Keçilerinde Eimeria Türlerinin Yaygınlığ1. Kocatepe Vet J. 2016; 9(4): 327-331. 


\section{GİRİ̧̧}

Eimeria soyuna bağlı apicomplexan protozoonların neden olduğu coccidiosis, bütün dünyada keçilerde s1kça rastlanan paraziter hastalıklardan biridir (Silva ve ark., 2014). Ookistler dişkıyla dışarı atılır ve uygun çevresel şartlarda sporlanarak enfektif hale gelirler. Enfeksiyon sporlanmış ookistlerin ağız yoluyla alınması suretiyle oluşmaktadır. Çevreyle ilgili uygun koşulların oluşması (Sicaklık, nem, oksijen), yetiştirme teknikleri ve hayvanın bağışıklık sistemi gibi koşullar enfeksiyonun şiddetini etkilemektedir (Cavalcante ve ark., 2012). Coccidiosis enfekte oğlaklarda yüksek oranda ölüme yol açması, ağırlık kazancinda azalmaya neden olmasi nedeniyle ekonomik kayıplara yol açmaktadır (Lima, 2004).Yetiştiricilik tekniğine bağl1 olarak keçilerde coccidiosis 4-10 haftalık oğlakların \% 100'ünü etkileyebilmekte bu durum keçi üretiminde önemli kayıpların ortaya çıkmasına neden olmaktadır (Ruiz ve ark., 2010). Ayrıca kalabalık ağıllar, sütten kesme, yem değişiklikleri, nakil, soğuk ya da sıcak havalar hastalığın diğer yaş gruplarında da ortaya çıkmasına ve sorun oluşturmasına neden olmaktadır (Gül, 2007). Hastalık, Eimeria ile enfekte oğlaklarda özellikle sütten kesme döneminde, şiddetli kanlı ishal ile birlikte kilo kayb1, sıv1 kayb1 ve büyümede gecikmeye yol açmaktadır (Koudela ve Bokova, 1998). Keçilerde coccidiosisin yayılişı ile ilgili çalışmalar bir çok türün kozmopolit ve çeşitli ülkelerde yaygın olduğunu ortaya koymuştur. Dünyanın farklı bölgelerinde keçilerde 17 Eimeria türünün bulunduğu bildirilmiş, bunlardan Eimeria christenseni, E.arloingi, E.caprina ve E.ninakohlyakimovae türleri oldukça patojen türler olarak açıklanmıştur (Kheirandish ve ark., 2014). Keçilerde coccidiosis genelde tüm hayvanlarda olduğu gibi gençler yani oğlaklar için önem taşır. Enfeksiyon nadiren tek türle, çoğunlukla birkaç türle kendini gösterir. Hastalığın klinik semptomları ve patojenitesi, bu türlerin en patojenine aittir ve iyileşen konakta bu türe karşı bağışıklık şekillenir. Oğlaklarda bazı Eimeria türleri genellikle ince bağırsakların değişik bölgelerinde gelişirken, baz1 türler (E.alijevi, E.apsheronika, E. minasensis ve E.ninakohlyakimovae) hem ince bağırsak hem de kalın bağırsakta gelişirler. Ancak son yıllarda bazı araştırıcılar, özellikle doğal ortamda barındırılan keçilerde karaciğerde Eimeria sp.'nin gelişme şekillerine rastladıklarını bildirmişlerdir (Dinçer ve Vatansever, 2001). Çeşitli ülkelerde yapılan çalışmalar keçilerde coccidiosisin yetiştirildiği tüm ülkelerde yaygın olduğunu, bu hayvanların \% 38-100 arasında çeşitli türlerle enfekte olduklarını göstermiştir (Dinçer ve Vatansever, 2001). Türkiye'de keçilerde coccidiosis konusunda sınırlı sayıda çalışma yapılmıştır (Sayın 1964, Sayın ve ark., 1980, Sayın ve ark., 1986, Güler ve ark., 1990, Değer ve ark., 2003, Göz ve ark., 2006). Değer ve arkadaşlar1 (2003) keçilerde E.arloingi (\% 47.43),
E.christenseni (\% 45.14), E.ninakohlyakimovae (\% 36.00), E.alijevi (\% 26.85), E.hirci (\% 23.42), E.caprina (\% 18.28), E.caprovina (\% 16.57), E.pallida (\% 13.14), E.jolchijevi $(\%$ 10.28) ve E.apsheronica (\% 3.42) türlerini tespit etmişlerdir. Göz ve arkadaşları (2006) ise E.arloingi (\% 41.5), E.alijevi (\% 37.7), E. christenseni (\% 20.7), E. ninakohlyakimovae (\% 18.9), E.pallida (\% 9.4), E. apsheronica (\% 9.4) ve E.birci (\% 7.5) türlerini saptamışlardır.

Oğlaklar genellikle sütten kesildikten ve meraya çıtıktan bir kaç hafta sonra coccidiosise yakalanırlar, bunda meranın yaşlı hayvanlar tarafindan çıkarılan ookistlerle kontaminasyonu büyük önem taşır. Ayrıca kalabalık bir şekilde bir arada barındırılan oğlaklarda da hastalığa yakalanma riski yüksektir. Besi için ağıllara alınan hayvanlar kısa sürede coccidiosise yakalanabilirler. Yeni doğan oğlakların anneleri ile birlikte olmaları da hastalı̆ga yakalanmaları için bir faktördür (Dinçer ve Vatansever, 2001). Kuzu ve oğlaklarda coccidiosis şekillenmesinde alınan ookist say1sı önemli olduğu gibi, beslenme tipi de hastalığın ortaya çıkışında önemli bir faktördür. Hayvanların beslenme tipinde yapılan ani değişikliklerde barsak epitel hücrelerinin Eimeria türlerinin invazyonuna karşı direncini azaltır, buna karşın besinler arasındaki geçişlerin düzenli ayarlandığı beslenmeler ise klinik coccidiosisin oluşumunda etkili bir koruma sağlar (Dinçer ve Vatansever, 2001). Besi ünitelerine ilk getirilişte genellikle dışkıdaki oosist sayısı az olmakla birlikte kalabalık yetiştirme ve yemin dışkı ile kontaminasyonu coccidiosis için elverişli koşullardır (Levine, 1985). Salginlar, hayvanların hijyenik olmayan ahirlarda bir arada tutulduğu durumlarda, veya merada yoğun otlatmada dişi ve yavruların bir arada tutulduğu durumlarda ortaya çıkar. Oğlaklarda diğer enfeksiyöz ajanlar, beslenme bozukluğu, stress ve çevre koşullanının yetersizliği coccidiosisin patojenitesini artırıcı faktörlerdir. Keçilerde coccidiosis ile ilgili daha az bilgi olmasına ve türlerin bir kısmının sadece dışkıda bildirilmesine rağmen, E.arloinginin yoğun bir patogeneze neden olduğu bilinmektedir. Keçilerde coccidiosis yetiştirildikleri her ülkede zaman zaman epidemik salgınlar şeklinde görülebilmektedir (Dinçer ve Vatansever, 2001).

Bugüne kadar Afyonkarahisar ilindeki keçilerde, coccidiosis üzerine herhangi bir çalışmaya rastlanmamıştır. Bu çalışma ile, süt ve döl verimi yüksek Saanen keçilerinde Eimeria türlerinin yaygınlığ1 araştırılarak hastalığın önlenmesinde alınacak korunma ve kontrol yöntemlerine katkıda bulunma amaçlanmıştur.

\section{MATERYAL VE METOT}

Çalışma, 09.06.2016-09.08.2016 tarihleri arasında Afyonkarahisar ilindeki bir çiftlikte yetiştirilen 1 yaşın altındaki Saanen keçilerinden alınan 187 adet dışk1 numunesi üzerinde gerçekleştirilmiştir. Herbir dışk1 numunesi rektumdan direkt alınarak plastik dişk1 
kaplarına konulmuş, hayvanın yaşı ve cinsi gibi protokol bilgileri de kaydedilmiştir. Laboratuvara getirilen dişk1 numunelerinden, her keçiye ait dişk1 örneği Fulleborn'un doymuş tuzlu su metodu ile incelenmiştir. Pozitif çıkan dişk1 numunelerinde Eimeria ookistlerinin kantitatif olarak saptanmas1 amacıyla Modifiye McMaster Yöntemi kullanılmıştır. Homojen olarak karışmış örnek dişkıdan $3 \mathrm{~g}$ alınarak $42 \mathrm{ml}$ flotasyon sıvısı ile karıştırılmış ve çay süzgecinden süzülmüştür. Filtrasyon işleminden hemen sonra pastör pipeti ile süspansiyondan bir miktar alınarak önceden hazırlanmış olan McMaster lamının her iki gözüne dikkatlice damlatılmıştır. Lam 3-5 dakika bekletilerek ookistlerin yüzmesi sağlanmıştır. McMaster lamının her iki bölmesindeki ookistler sayılarak ortalaması alınmış ve gram dışkıdaki ookist miktarı (OPG) hesaplanmıştır. Dişkıda bu metotla, Eimeria ookistleri tespit edilen dışkı örneklerinden bir miktar alınmış çeşme suyu ile karıştırılmış iyice ezilmiş ve süzgeçten geçirildikten sonra ayr1 ayrı petri kutulanna aktarılmış, bu petri kutularının üzerine \% 2.5 Potasyum dikromat ilave edildikten sonra laboratuvarda sporlanmaya bırakılmıştır. Sporlanmış ookistler tür teşhisleri yapılıncaya kadar + 4 C'de muhafaza edilmiştir. Daha sonra sporlanmış ookistlerin ölçümü, santrifüj flotasyon tekniği kullanılarak Nikon Eclipse i-Series 80i trinoküler araştırma mikroskobunun x100'lük büyütmesinde DS-5M-L1 dijital kamera sistemi ile mikrometrik olarak yapılmıştır. Bu amaçla dışkı süspansiyonu 15 ml'lik santrifüj tüplerine aktarılıp 1500 rpm'de 5 dakika santrifüj edilmiştir. Üst s1v1 atıldıktan sonra geriye kalan çökelti üzerine bir miktar flotasyon sıvisı aktarılarak tüp uygun bir kapakla kapatılıp çökelti iyice karışana kadar çalkalanmış, tüp ağzına kadar flotasyon sıvısı ile tamamlanmıştur. Tüp üzerine lamel kapatılıp 1500 rpm'de 5 dakika santrifüj edilmiştir. Daha sonra lamel dikkatlice alınıp lam üzerine konduktan sonra Eimeria ookistlerinin tür ayırımları, literatürlerde bildirilen ookistlerin şekli, rengi, büyüklüğü, cidarının durumu, sporokistlerin ve sporozoitlerin şekli ve büyüklüğü, sporokist ve ookist kalıntısı, stidea cisimciği, kutup granülü, mikropil, kep ve refraktil globüllerin mevcut olup olmadiklan immersiyon objektifi altında incelenerek yapılmıştır.

\section{SONUÇLAR}

Eimeria ookistleri 187 keçinin 74 (\% 39.6)'de tespit edilmiştir. Yapılan incelemeler sonucunda, Eimeria caprina, E.ninakohlyakimovae, E. aspheronica, E. caprovina, E. alijevi, E.jolchijevi, E. christenseni ve E. arloingi olmak üzere 8 Eimeria türü teşhis edilmiştir. En yayg1n türlerin Eimeria caprina (43.2 \%) ve E.ninakohlyakimovae (33.8 \%) türleri olduğu belirlenmiştir. (Table 1).
Tablo 1: Afyonkarahisar ilinde Saanen keçilerinde Eimeria türlerinin yaygınlığ1

Table 1: Prevalence of Eimeria species in Saanen goats in Afyonkarahisar province

\begin{tabular}{llc}
\hline Eimeria türleri & $\begin{array}{l}\text { Enfekte } \\
\text { keçi sayıs }\end{array}$ & $\begin{array}{c}\text { Enfeksiyon oranı } \\
(\%)\end{array}$ \\
\hline Eimeria caprina & 32 & 43.2 \\
E.ninakoblyakimovae & 25 & 33.8 \\
E. aspheronica & 19 & 25.7 \\
E. caprovina & 16 & 21.6 \\
E. alijevi & 14 & 18.9 \\
E.jolchijevi & 4 & 5.4 \\
E. christenseni & 2 & 2.7 \\
E. arloingi & 2 & 2.7 \\
$\begin{array}{l}\text { Teşhis edilemeyen } \\
\text { Eimeria spp. }\end{array}$ & 9 & 12.2 \\
\hline
\end{tabular}

Gram dışkıdaki ookist sayısı (OPG) 2-1276 arasında bulunmuş, keçilerde herhangi bir klinik bulguya rastlanmamıştır. Muayene edilen 187 keçinin \% 39.6's1 bir yada daha fazla Eimeria türü ile enfekte bulunmuştur. Miks enfeksiyonlar muayene edilen keçilerin \% 20.3'ünde belirlenmiștir. Tek türle enfeksiyon \% 19.3, iki türle enfeksiyon $\% 11.2$, üç türle enfeksiyon $\% 6.4$ ve dört türle enfeksiyon \% 2.7 olarak saptanmıştır. Muayene edilen keçilerin 13 'ünde (\% 60.4) ise ookiste rastlanılmamıştır (Tablo 2).

Tablo 2: Farklı Eimeria türleri ile enfekte keçi sayıları ve enfeksiyon yüzdeleri

Tablo 2:The number of infected goats with different Eimeria species and infection rates

\begin{tabular}{lccccc}
\hline & \multicolumn{6}{c}{ Eimeria türlerinin say1s1 } \\
\hline \multirow{2}{*}{ Enfekte keçi sayıs1 } & 0 & 1 & 2 & 3 & \multicolumn{1}{c}{4} \\
\cline { 2 - 6 } & 113 & 36 & 21 & 12 & 5 \\
Yüzde (\%) & 60.4 & 19.3 & 11.2 & 6.4 & 2.7 \\
& & & & & \\
\hline
\end{tabular}

\section{TARTIŞMA}

Dünyanın farklı bölgelerinde keçilerde 17 Eimeria türünün bulunduğu bildirilmiştir (Kheirandish ve ark., 2014). Türkiye'nin değişik bölgelerinde keçilerde yapılan çalışmalarda E.arloingi, E.christensini, E.ninakobliyakimovae, E. alijevi, E.birci, E.caprina, E.caprovina, E.pallida, E.jolchijevi ve E. apsheronica olmak üzere 10 Eimeria türü teşhis edilmiştir (Sayın 
1964, Sayın ve ark., 1980, Sayın ve ark., 1986, Güler ve ark., 1990, Değer ve ark., 2003, Göz ve ark., 2006, Gül 2007). Afyonkarahisar ilindeki keçilerde görülen Eimeria türleri ve prevalans değerleri konusunda ilk defa gerçekleştirilen bu çalışmada, Eimeria caprina, E.ninakoblyakimovae, E. aspheronica, E. caprovina, E. alijevi, E.jolchijevi, E. christenseni ve E. arloingi olmak üzere 8 Eimeria türü teşhis edilmiştir. Çeşitli ülkelerde yapılan çalışmalarda keçilerde koksidiyal enfeksiyonun prevalans değerleri \% $\quad 15.28-\% 98.61$ arasında tespit edilmiştir (Norton 1986, Al-Amery ve Hasso 2002, Cavalcante ve ark., 2012, Silva ve ark., 2014). Türkiye'de yapılan çalışmalarda ise prevalans değerleri \%53.3-\% 94.8 arasında saptanmıştır (Merdivenci 1959, Say1n 1964, Güler ve ark., 1990, Değer ve ark., 2003, Göz ve ark., 2006, Gül 2007). Afyonkarahisar ilinde Saanen keçilerinde gerçekleştirilen bu çalışmada prevalans değeri \% 39.6 olarak bulunmuştur. Prevalans değerleri arasındaki farklılıkta hayvanların yaşı, bakım ve besleme şartları, araştırmanın yapıldığı bölgeler arası iklimsel farklılık gibi faktörlerin etkili olduğu düşünülmektedir.

Keçilerde varlığ1 bildirilen Eimeria christenseni, E.arloingi, E.caprina ve E.ninakoblyakimovae türleri oldukça patojen türler olarak açıklanmıştur (Kheirandish ve ark., 2014). Türkiye'de değişik bölgelerde yapılan çalışmalarda E.arloingi (\%31.38$\% 47.43)$ ve E.christensini (\%29.78- \% 45.14) türleri yaygın olarak belirlenirken bu çalışmada Eimeria caprina (43.2 \%) ve E.ninakoblyakimovae (33.8\%) türlerinin daha yaygın olduğu saptanmıştır. Çeşitli araştırmacıların yaptıkları çalışmalarda miks enfeksiyonlara sık rastlanmıştır (Chhabra ve Pandey 1991; Değer ve ark., 2003; Göz ve ark., 2006; Gül 2007). Bu çalışmada tek türle enfeksiyon (\% 19.3) daha yaygin bulunmuştur.

\section{SONUÇ}

Muayene edilen keçilerin \% 39.6'sının farklı Eimeria türleri ile enfekte bulunduğu bu çalışamada, döl verimi yüksek olan Saanen keçilerinde subklinik enfeksiyonların dikkate alınması gerektiği kanaatine varılmıştır.

\section{KAYNAKLAR}

Al-Amery MAY, Hasso SA. Laboratory diagnosis of novel species of Theileria hirci, Eimeria caprovina and Eimeria pallida in goats in Iraq. Small Ruminant Res. 2002; 44: 163-166.

Cavalcante ACR, Teixeira M, Monteiro JP, Lopes CWG. Eimeria species in dairy goats in Brazil. Vet Parasitol. 2012; 183: 356-358.
Chhabra RC, Pandey VS. Coccidiosis in goats in the Czech Republic. Vet Parasitol. 1991; 39:199-205.

Dinçer Ş, Vatansever Z. Koyun ve Keçilerde Coccidiosis, In: Coccidiosis, Ed; Dinçer Ş. Türkiye Parazitoloji Derneği Yayın No : 17, 2001; 219-233.

Deger S, Gul A, Ayaz E, Bicek K. The prevalence of Eimeria species in goats in Van. Turk J Vet Anim Sci. 2003; 27: 439-442.

Güler S, Dumanlı N, Özer E, Erdoğmuş N, Köroğlu E. Elazı̆̆ yöresinde kuzu ve oğlaklarda bulunan Eimeria türleri ve bunların yayılışı üzerine araştırmalar. Doğa $\operatorname{Tr} \mathrm{J}$ Vet Anim Sci. 1990; 14, 295-300.

Göz Y, Aydın A, Yuksek N, Deger S. Frequency of coccidian species in goats in Van province of Turkey. Kafkas Univ Vet Fak Derg. 2006; 12 (2): 163-165.

Gül A. The prevalence of Eimeria species in goats in Iğdır. Turk J Vet Anim Sci. 2007; 31 (6): 411 414.

Kheirandish R, Nourollahi-Fard SR, Yadegari Z. Prevalence and pathology of coccidiosis in goats in southeastern Iran. J Parasit Dis. 2014; 38 (1): 27-31.

Koudela B, Bokova A. Coccidiosis in goats in the Czech Republic. Vet Parasitol. 1998; 76 (4): 261-267.

Levine ND. Veterinary Protozoology. Iowa State University Press, 1985, USA.

Lima JD. Coccidiose dos ruminantes domesticos. Rev Bras Parasitol Vet. 2004; 13 (S1): 9-13.

Merdivenci A. Evcil koyun (Ovis aries) ve keçi (Capra bircus)'lerimizde Coccidia nevileri ve baz1 deneyler. Türk Vet. Hek. Dern. Derg. 1959; 29: 260-281.

Norton CC. Coccidia of domestic goat, Capra hircus, with notes on Eimeria ovinoidalis and E.bakuensis (E.ovina) from the sheep, Ovis aries. Parasitology, 1986; 92: 279-289.

Ruiz A, Behrendt JH, Zahner H, Hermosilla C, Perez D, Matos L. Development of Eimeria ninakohlyakimovae in vitro in pirimary and permanent cell lines. Vet Parasitol. 2010; 173 (1-2): 2-10. 
Sayın F. Eimeria ninakoblyakimovae, yakimof and rastegaieff 1930, in Angora goats. Ankara Üniv Vet Fak Derg. 1964; 11, 136-144.

Sayın F, Dincer S, Milli U. The life cycle and pathogenicity of Eimeria arloingi (Marotel, 1905) Martin, 1909, in Angora kids and an attemt at its transmission to lambs. Zentrabl Vet Med. 1980; 27: 382-397.

Sayın F, Kahyaoğlu T, Çakmak A. Ege bölgesinde (İzmir, Manisa, Aydın) koyun ve keçilerde Eimeria türlerinin tesbiti. Ankara Univ Vet Fak Derg. 1986; 33 (1): 90-9.

Silva LMR, Vila-Viçosa MJM, Nunes T, Taubert A, Hermosilla C, Cortes HCE. Eimeria infections in goats in Southern Portugal. Bra\%: J Vet Parasitol, 2014; 23 (2): 280-286. 